National Marine

Fisheries Service

NOAA
Fishery Bulletin

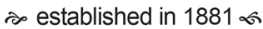

Spencer F. Baird

First U.S. Commissione of Fisheries and founder of Fishery Bulletin
Abstract-We examined the feasibility of distinguishing trawlable from untrawlable bottom using acoustic backscatter data from a calibrated single-beam echosounder to better define and map continental shelf areas of the Gulf of Alaska (GOA) that are too rough and rocky to be sampled by the National Marine Fisheries Service's biennial bottom trawl groundfish survey. Bottom classification algorithms were applied to backscatter data collected from areas of known trawlability to provide 9 metrics of bottom type from small sections of bottom ( $~ 50$ records within a 15-min trawl tow). Prediction models, based on both generalized additive models (GAMs) and generalized linear models (GLMs), were developed to relate the bottom type metrics to the known state of trawlability. The models were then tested to judge their performance on new data by using $33 \%$ cross validation. Although the best GAM had a higher correct prediction rate $(82.4 \%)$ than the best GLM (76.9\%), under cross validation both models had nearly the same correct prediction rate $(75.0 \%)$. This result is a sufficiently high prediction rate to allow the development of better trawlability maps by applying the model to data collected along acoustic track lines during the GOA bottom trawl surveys.

Manuscript submitted 16 December 2016 . Manuscript accepted 8 August 2017.

Fish. Bull. 115:496-503 (2017).

Online publication date: 16 August 2017. doi: 10.7755/FB.115.4.6

The views and opinions expressed or implied in this article are those of the author (or authors) and do not necessarily reflect the position of the National Marine Fisheries Service, NOAA.

\title{
A method for predicting trawlability in the Gulf of Alaska with the use of calibrated, split-beam, echosounder backscatter
}

\author{
Paul G. von Szalay (contact author) \\ David A. Somerton \\ Email address for contact author: paul.von.szalay@noaa.gov \\ Resource Assessment and Conservation Engineering Division \\ Alaska Fisheries Science Center \\ National Marine Fisheries Service, NOAA \\ 7600 Sand Point Way NE \\ Seattle, Washington 98115
}

The Alaska Fisheries Science Center of the National Marine Fisheries Service has conducted a bottom trawl survey in the Gulf of Alaska (GOA) biennially since 1999 to assess the distribution and abundance of groundfish for fisheries management (von Szalay and Raring, 2016). The survey area, which consists of 59 strata based on depth, benthic habitat, and management areas, spans the continental shelf and upper continental slope from the Islands of Four Mountains eastward to Dixon Entrance, and from nearshore waters to a depth of $1000 \mathrm{~m}$ (Fig. 1). Although the purpose for the survey is to randomly sample this area under the assumption that the entire area is trawlable (can be sampled with the Poly-Nor'eastern 4-seam survey trawl), in practice, this concept is an approximation because the GOA is a mosaic of habitat types. Some habitats are untrawlable; that is, they are too rocky, rugged, or steep to allow a fully random choice of sampling locations when using the standard survey trawl. Furthermore, the GOA has never been mapped with sufficient spatial resolution to permit identification of bottom types that would preclude successful trawling. Consequently, the locations of untrawlable bottom (in the varying opinions of experienced GOA survey vessel captains) and even the proportion of the area comprising such habitat is not known. The relative abundance of each species is therefore currently estimated by extrapolating the mean abundance in trawlable areas to the entire survey area. A potential problem with this approach is that it may result in biased estimates of abundance because fish density is a function of habitat type, which is correlated with trawlability (Yoklavich et al., 2000; Pirtle et al., 2015). The bias is likely positive for flatfish and other fish species, which prefer relatively smooth and sandy bottoms in trawlable habitats (McConnaughey and Smith, 2000; Busby et al., 2005), and negative for rockfish (Sebastes spp.) and other fish species, which prefer rough, rocky bottoms in untrawlable habitats (Richards, 1986; Stein et al., 1992; Clausen and Heifetz, 2002; Jagielo et al., 2003; Zimmermann, 2003; Jones et al., 2012).

An alternative survey design now being considered by the Alaska Fisheries Science Center for the GOA is one in which the abundance estimates derived from survey trawl catches, based on catch weight per unit of swept area, would be extrapo- 


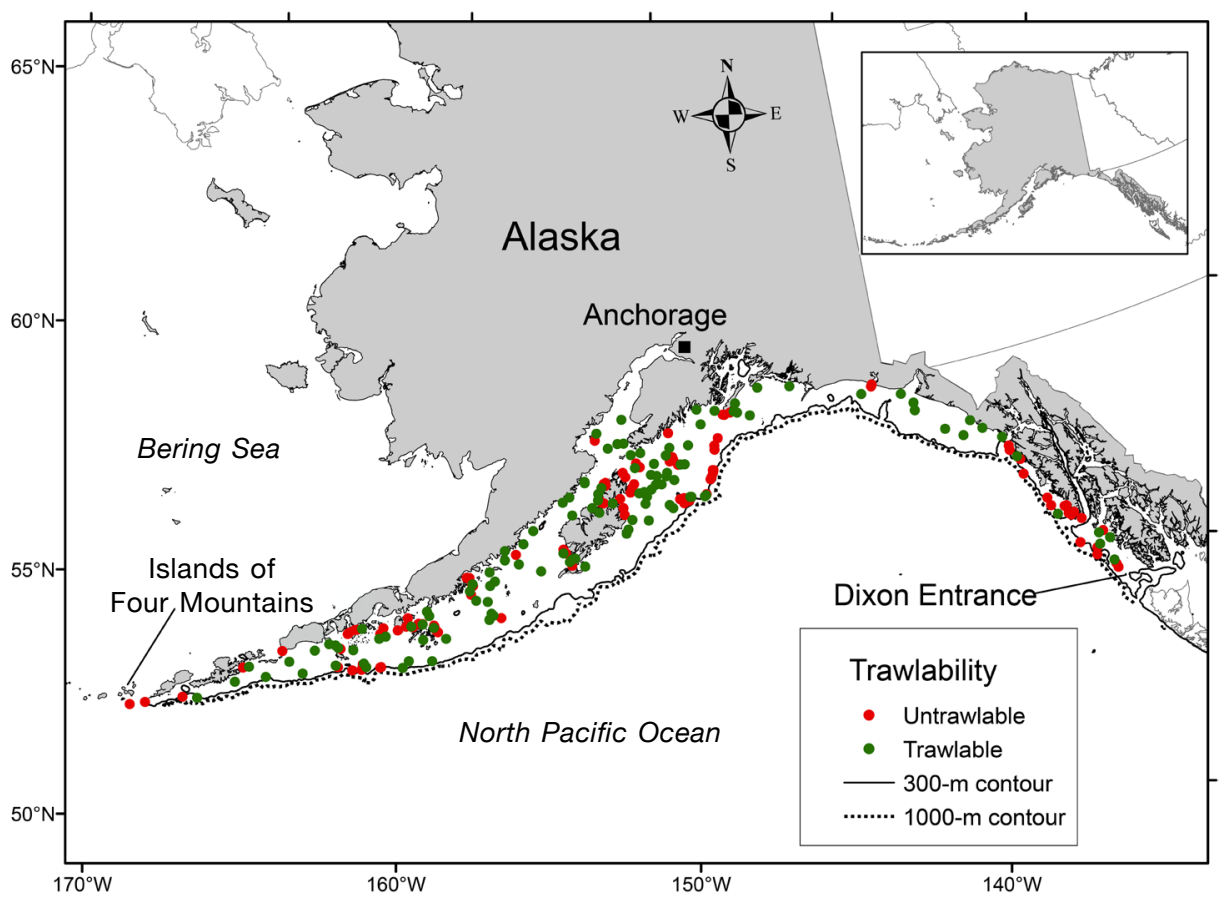

Figure 1

Map of the survey area for the bottom trawl survey conducted biennially in the Gulf of Alaska by the National Marine Fisheries Service since 1999, confined by the $1000-\mathrm{m}$ isobath (dotted line). The area confined by the $300-\mathrm{m}$ isobath (solid line) represents the area where acoustic data within a grid of cells were used to predict trawlability. Green circles represent acoustic data segments from trawlable areas, and red circles represent acoustic segments from untrawlable areas.

lated only to areas that are trawlable, and some new sampling methods (e.g., the use of acoustic, longline, or camera gear) would be applied to the untrawlable areas (Rooper et al., 2010; Williams et al., 2010; Jones et. al., 2012; Thorson et al., 2013). To implement this sampling design, the relative proportions of trawlable and untrawlable areas must be known, proportions that require a technique for identifying and quantifying trawlable and untrawlable habitats (Cordue, 2007).

Previously, the approach to identify the trawlability status of an area was based on the historical performance of the survey within individual cells of a grid of $5 \times 5 \mathrm{~km}$ cells superimposed on the survey area. These cells, which number $\sim 14,000$, are the potential sampling units of the survey. To be considered trawlable, a sampling cell must have been successfully trawled (with a Poly-Nor'eastern 4-seam survey trawl in standard fishing configuration and without sustaining any damage throughout the tow) by a survey vessel during a prior GOA bottom trawl survey. To be considered untrawlable, a sampling cell must be judged so on the basis of the vessel captain's assessment of the echogram, which is a real-time image of the backscatter data collected from a hull-mounted single-beam echosounder on a survey vessel. Any seabed feature that a vessel captain deems likely to result in moderate to severe damage to fishing gear or prevents the fishing gear from maintaining proper configuration and bottom contact throughout a tow provides a valid reason for declaring a sampling cell untrawlable. Nine categories of untrawlable seabed features have been identified: 1) hard+rocky substrate, 2) steep slopes, 3) rolling seabed, 4) pinnacles, 5) unnavigable areas, 6) snags, 7) ledges, 8) presence of underwater cable, and 9) presence of fixed fishing gear.

Captains of survey vessels have learned to recognize bottom features visible on echosounder traces and that could damage a survey trawl (Poly-Nor'eastern 4-seam bottom trawl with roller gear; Stauffer, 2004). Therefore, a sampling cell is classified as untrawlable if the captain fails to find a suitable bottom, at least $1 \mathrm{~km}$ in length, after systematically searching a sampling cell for $2 \mathrm{~h}$, a duration that is considered sufficient to cover a sampling cell. Although consistent with the operational survey procedures of the bottom-trawl survey, this approach provides a qualitative and relatively slow assessment of seafloor character (only $42 \%$ of the survey area classified by this method to date).

We are exploring the use of acoustics to detect bottom features associated with trawlability to increase 
the rate and precision at which the bottom-trawl survey sampling cells are classified to improve our ability to efficiently sample areas that are trawlable and avoid untrawlable ground. One approach described by Weber et al. (2013) and Pirtle et al. (2015), involves modeling trawlability as a function of seafloor metrics derived from bathymetry and backscatter data collected from multibeam acoustic surveys conducted by the National Marine Fisheries Service. Because no multibeam acoustic data are collected during the GOA trawl survey, we considered another method for this study, one that is based on the analysis of calibrated, single-beam acoustic backscatter data. The Alaska Fisheries Science Center has routinely collected these data since 2005 on all chartered fishing vessels used to conduct the bottom trawl survey. Although single-beam acoustic backscatter from the seabed has been analyzed in a number of studies to distinguish a variety of habitat types (Kloser et al., 2001; Anderson et al., 2002; Freitas et al., 2003; Riegl et al., 2005; Bartholomä, 2006), we consider the response variable as binary, as simply distinguishing between trawlable and untrawlable bottoms. The objectives for this study were 1) to examine the feasibility of developing a trawlability prediction model based on backscatter data from areas of known trawlability and 2) to evaluate the use of applying the model to predict trawlability in unknown areas on the basis of measured backscatter properties of acoustic data collected along track lines of future surveys conducted by the same vessel and with the same echosounder that was used to collect data for this study.

\section{Materials and methods}

The acoustic data were collected aboard the 38.4-m stern trawler FV Sea Storm during the 2013 GOA bottom trawl survey by using a Simrad ${ }^{1}$ ES60 echosounder (Kongsberg Maritime AS, Horten, Norway) equipped with a $7.1^{\circ}$ beam width, $38-\mathrm{kHz}$, split-beam transducer, which operated at a ping rate of $1 \mathrm{~Hz}$ and pulse duration of $1.024 \mathrm{~ms}$. The echosounder was calibrated on-axis with a copper sphere according to standard procedures described by Foote et al. (1983). A total of 238 individual acoustic data segments were used in the analysis, half from trawlable and half from untrawlable areas. The trawlable and untrawlable segments were randomly selected from a pool of segments spanning the entire range of the survey area that satisfied the basic criteria identified in the next paragraph for the sampling cells containing the segments (Fig. 1). An acoustic data segment is an echosounder-insonified section of a vessel track line, and all segments from both trawlable and untrawlable areas consisted of data collected over 15-min time intervals, corresponding to the duration of a standard trawl haul. Although the

\footnotetext{
${ }^{1}$ Mention of trade names or commercial companies is for identification purposes only and does not imply endorsement by the National Marine Fisheries Service, NOAA.
}

depth range of the biennial bottom trawl groundfish survey extends to water depths as deep as $1000 \mathrm{~m}$, the depths associated with the segments of this specific study were all less than $300 \mathrm{~m}$ because unacceptably slow ping rates (producing poor echogram resolution of the seabed) are required for deeper depths. Depths less than $300 \mathrm{~m}$ comprised $90 \%$ of the survey area (Fig. 1).

As with the selection process for trawlable and untrawlable segments, the sampling cells containing the selected segments were chosen randomly from a pool of cells satisfying certain criteria. Among the trawlable cells, only sampling cells that represented areas that had been successfully towed without any documented incidents such as tears in nets or trawl door entanglements with the bottom on at least 2 separate surveys were included in the analysis. Among the untrawlable cells, only sampling cells classified as untrawlable owing to 1 of the 5 hard or rough categories, or combination categories (i.e., hard+rocky, rolling seabed, pinnacles, snags, ledges) were used in the analysis. Cells classified as unnavigable were not used because acoustic data cannot be collected from areas that the survey vessel cannot navigate. Furthermore, the fixed fishing gear and underwater cable categories are for cells with manmade obstructions; these cells do not necessarily have acoustic signatures that identify them as untrawlable, yet it would be ill advised to trawl in these areas. Another major reason for considering an area untrawlable is that it is considered too steep. However, for the purposes of this analysis, such cells were not considered because acoustic features associated with steep slopes have been shown to be distinct from those of more level areas, regardless of substrate type (von Szalay and McConnaughey, 2002). Furthermore, steep slope areas are primarily confined to relatively deep waters $(>200)$, and the models developed in this study are intended only for use in the continental shelf portion of a survey area.

The raw acoustic data files were processed before analysis to remove noise in the form of triangle wave dither that degrades the ES60-generated raw files, by using the known period and amplitude of the dither (Ryan and Kloser ${ }^{2}$ ). The triangle wave-corrected raw files were subsequently analyzed by using the seabed classification module in Echoview, vers. 6.1.72 (Echoview Software, Pty. Ltd., Hobart, Australia). Seven settings, which are used by an algorithm within the software to detect the bottom by using the data collected (bottom line pick), were specified before we derived classification data. The values of the settings used in this study (Table 1) were the defaults recommended by Echoview under most circumstances, except for the value for the minimum volume backscatter strength (min $\mathrm{S}_{\mathrm{v}}$ for good pick), which was modified for this study after consulting with an Echoview Software represen-

\footnotetext{
${ }^{2}$ Ryan, T., and R. Kloser. 2004. Quantification and correction of a systematic error in Simrad ES60 echosounders, 9 p. ICES FAST, Gdansk. [Available from Marine and Atmospheric Research, Commonwealth Scientific Industrial Research Organisation, GPO Box 1538, Hobart, TAS 7001, Australia.]
} 


\section{Table 1}

Settings of the bottom-line-picking algorithm in Echoview software used before classification of seabed habitats. These values "told" the software how to detect the bottom (pick the bottom line) in the acoustic data collected during the National Marine Fisheries Service biennial bottom trawl survey of the Gulf of Alaska.

\begin{tabular}{lc}
\hline Setting & Value \\
\hline Start depth $(\mathrm{m})$ & 10 \\
Stop depth $(\mathrm{m})$ & 500 \\
Min $\mathrm{S}_{\mathrm{v}}$ for good pick $(\mathrm{dB})$ & -80.00 \\
Discrimination level & -40.00 \\
Back step range & 0.00 \\
Peak threshold (dB) & -40.00 \\
Minimum threshold (dB) & -70.00
\end{tabular}

tative. Next, the Echoview algorithm for background noise removal was applied to the data by using a signal-to-noise ratio setting of 10 and a maximum noise level subject to a removal setting of $0 \mathrm{~dB}$. Echoview algorithms for bottom classification were then used to derive the 9 standard feature parameters from the first and second echo returns of the signal from the bottom. Echoview Software has determined that these feature parameters distinguish general seabed features. No attempt was made to narrow the 9 features down to those believed to be most relevant in distinguishing trawlability. The bottom echo threshold at $1 \mathrm{~m}$, which is used to determine the end of the first and second echoes, was set to $-125 \mathrm{~dB}$ and the reference normalization depth was set to $300 \mathrm{~m}$.

The names of the feature parameters derived from the first echo are: roughness, first bottom length, bottom rise time, depth, maximum $\mathrm{S}_{\mathrm{v}}\left(\max \mathrm{S}_{\mathrm{v}}\right)$, kurtosis, and skewness; the names of the parameters derived from the second echo are: hardness and second bottom length (Table 2). Information on how Echoview processes backscatter data, including definitions of the terms used to derive the 9 feature parameters, and equations defining the parameters can be found in the help file for the software (available from website). Each of the 238 acoustic data segments consisted of $\sim 50$ records, where a record is made up of the 9 acoustic feature parameter values derived from groups of 10 consecutive pings. In this study, a record is the basic classification unit of an acoustic segment. The parameter values of the individual records were modeled directly without using the classification feature in the Echoview bottom classification module, which uses principal component and cluster analyses to categorize individual records into a user-specified number of bottom types.

Trawlability was modeled as a function of the 9 acoustic feature parameters by using both generalized linear modeling and generalized additive modeling functions in $R$, vers. 3.2.0 ( $\mathrm{R}$ Core Team, 2015). A binomial error distribution was assumed for both types of models.

Three different classes of generalized linear models (GLMs) were evaluated by using the minimum value of the Akaike's information criterion (AIC) to choose the best-fitting model within each class (Table 3 ). The 3 classes consisted of models with all linear terms, mixtures of linear and polynomial terms, and mixtures of

\section{Table 2}

Definitions of the 9 standard parameters used in the Echoview algorithms for classification of seabed habitats. These feature parameters were covariates in all models used in this study to predict whether sampling areas in the Gulf of Alaska were trawlable. $\mathrm{X}=$ affirmative.

\begin{tabular}{lcc}
\hline Parameter & Definition & $\begin{array}{c}\text { Depth } \\
\text { normalized }\end{array}$ \\
\hline
\end{tabular}

First echo

Roughness

First bottom length

Bottom rise time

Depth

Max Sv

Kurtosis

Skewness

Second echo

Hardness

Second bottom length
Tail energy. Integration of the tail of the first echo. Exclusively due to incoherent backscattering from facets inclined towards the transducer Total duration of the first bottom echo (bottom line depth to bottom $\mathrm{X}$ echo threshold at $1 \mathrm{~m}$ ).

Attack duration (bottom line sample to the peak sample of the first echo). Water depth

Maximum energy. Maximum volume backscatter strength

Tailedness. Sharpness of the first echo peak

Asymmetry around the first echo peak

Total energy of the second echo (integration of the complete second acoustic bottom return).

Total duration of the second echo (bottom line depth to bottom echo threshold at $1 \mathrm{~m}$ ).

X

$\mathrm{X}$

$\mathrm{X}$




\section{Table 3}

Classes of generalized linear models (GLMs) and generalized additive models (GAMs) evaluated for goodness of fit in this study for the use of acoustic data to predict whether sampling areas in the Gulf of Alaska are trawlable. The best model in each category is shown in boldface. An asterisk (*) indicates an interaction term. The parameters include roughness, hardness, first bottom length (length 1), second bottom length (length 2), bottom rise time, depth, maximum volume backscatter strength (Sv), kurtosis, and skewness. NS=not significant; poly=polynomial ; $\mathrm{S}=$ smooth; $d=$ degree of polynomial; $\mathrm{k}=$ number of knots.

\begin{tabular}{|c|c|c|c|c|c|c|c|c|c|}
\hline & Roughness & Hardness & Length 1 & Length 2 & Rise time & Depth & Max Sv & Kurtosis & Skewness \\
\hline \multicolumn{10}{|l|}{ GLM } \\
\hline Model 1 & linear & linear & linear & linear & linear & linear & NS & linear & linear \\
\hline Model 2 & poly $(\mathrm{d}=3)$ & linear & poly $(\mathrm{d}=2)$ & linear & linear & linear & NS & linear & poly $(\mathrm{d}=2)$ \\
\hline Model 3 & linear & linear & *skewness & linear & linear & linear & linear & linear & *length 1 \\
\hline \multicolumn{10}{|l|}{ GAM } \\
\hline Model 1 & $\mathbf{S}()$ & $\mathbf{S}()$ & $\mathbf{S}()$ & $\mathbf{S}()$ & $\mathrm{S}()$ & $\mathbf{S}()$ & $\mathrm{S}()$ & $\mathbf{S}()$ & $\mathrm{S}()$ \\
\hline Model 2 & $\mathrm{~S}(\mathrm{k}=4)$ & $\mathrm{S}(\mathrm{k}=4)$ & $\mathrm{S}(\mathrm{k}=4)$ & $\mathrm{S}(\mathrm{k}=4)$ & $\mathrm{S}(\mathrm{k}=4)$ & $\mathrm{S}(\mathrm{k}=4)$ & NS & NS & $\mathrm{S}(\mathrm{k}=4)$ \\
\hline Model 3 & $\mathbf{S}()$ & $\mathrm{S}()$ & *skewness & $\mathbf{S}()$ & $\mathbf{S}()$ & $\mathrm{S}()$ & $\mathrm{S}()$ & $\mathrm{S}()$ & *length 1 \\
\hline
\end{tabular}

linear and interaction terms. When interaction terms were introduced, the choice of which terms to include in each interaction was based on their correlation. Specifically, the correlation between skewness and first bottom length, skewness and kurtosis, and between hardness and $\max \mathrm{S}_{\mathrm{v}}$ were high at $0.92,0.97$, and 0.82 , respectively, and were therefore examined for potential interaction effects. The step function in $R$, which calculates the AIC value of models starting with the full model that used all 9 parameters and then in a stepwise fashion eliminates 1 parameter at a time, was applied to each candidate model to determine whether a simpler, reduced model would result in a better fit. The best GLM among the 3 classes was then chosen as the one with the lowest AIC value.

Three classes of generalized additive models (GAMs) were also evaluated, again with the minimum AIC value to choose the best-fitting model within each class (Table 3). The 3 classes consisted of models with all unconstrained smoothing terms, models with constrained smoothing terms, and models with mixtures of unconstrained and bivariate smoothing terms (interaction terms). Constraining the smoothing functions consisted of setting the maximum number of knots allowed (in all cases, 4 knots). Choice of the variables used in the interaction terms was again based on the magnitude of the correlation between variables. Model selection for the GAMs proceeded with a process similar to that used for the GLMs, but was done manually because a step function is unavailable for GAMs. Instead, we used the $P$-values from the analysis of variance of the model to sequentially eliminate nonsignificant terms. In the event of more than 1 nonsignificant term, the term with the least significance was first eliminated, then the reduced model was refitted and further nonsignificant terms were sequentially removed. The best overall GAM was again chosen among the best models within each class on the basis of minimum AIC.
After selecting the best candidate GLM and GAM, we compared them in terms of their ability to correctly classify data not used in the model building process. The best model (i.e., the one with the highest predictive accuracy) when applied to the training data is not necessarily the best choice when applied to new data. To assess the relative robustness of the models when subjected to new data, we used $33 \%$ holdout cross validation (Arlot and Celisse, 2010; Maunder and Harley, 2011), which proceeded as follows. Random samples of 160 segments, split equally between trawlable and untrawlable data, were selected without replacement from the pool of 238 acoustic segments. These data were then used as a training sample to construct prediction functions by fitting the best GLMs and GAMs. The remainder of the sample was used as a proxy for new data. Each of the fitted models was then applied to the new data to estimate the probability that each of the $\sim 50$ records within each segment was trawlable by using the "predict" function in $R$. Probabilities $>0.5$ was used as a criterion to classify individual records as trawlable. Likewise, the criterion used to classify entire segments as trawlable was that the proportion of records classified as trawlable was also $>0.5$. After the trawlability of all segments was estimated, the values were compared with the trawlability classification of the sampling cells. The proportion of correctly classified segments was then calculated. This process was repeated 100 times and the average proportion of correct classification was used as a measure of how well each model predicted trawlability.

\section{Results and discussion}

On the basis of the minimum value of AIC, the best GAM, with 7 unconstrained smoothing terms and 1 interaction term, produced an overall (trawlable and 


\begin{tabular}{|c|c|c|c|c|c|}
\hline \multicolumn{6}{|c|}{ Table 4} \\
\hline \multicolumn{6}{|c|}{$\begin{array}{l}\text { Goodness of fit, based on Akaike's information criterion (AIC), prediction accuracy of untrawlable } \\
\text { and trawlable sampling cells (sampling units) in the survey area, overall prediction accuracy, } \\
\text { and prediction accuracy after cross-validation of the } 3 \text { generalized linear models (GLMs) and } \\
3 \text { generalized additive models (GAMs) evaluated in this study for the use of acoustic data to } \\
\text { predict whether sampling areas in the Gulf of Alaska are trawlable. The best model in each } \\
\text { category is shown in boldface. }\end{array}$} \\
\hline & AIC & $\begin{array}{l}\text { Untrawlable } \\
\text { prediction } \\
\text { rate }(\%)\end{array}$ & $\begin{array}{l}\text { Trawlable } \\
\text { prediction } \\
\text { rate }(\%)\end{array}$ & $\begin{array}{l}\text { Overall } \\
\text { prediction } \\
\text { rate }(\%)\end{array}$ & $\begin{array}{c}\text { Cross } \\
\text { validation } \\
\text { prediction }(\%)\end{array}$ \\
\hline \multicolumn{6}{|l|}{ GLM } \\
\hline Model 1 & 12,353 & 82.0 & 70.6 & 76.3 & \\
\hline Model 2 & 12,230 & 84.0 & 69.7 & 76.9 & 75.0 \\
\hline Model 3 & 12,351 & 84.0 & 71.4 & 77.7 & \\
\hline \multicolumn{6}{|l|}{ GAM } \\
\hline Model 1 & 10,435 & 81.5 & 82.4 & 82.0 & \\
\hline Model 2 & 11,496 & 81.9 & 75.2 & 78.6 & \\
\hline Model 3 & 10,343 & 81.5 & 83.2 & 82.4 & 75.0 \\
\hline
\end{tabular}

untrawlable segments combined) classification accuracy of $82.4 \%$ (Table 4 ). In contrast, the best GLM with 5 linear terms and 3 polynomial terms, but no interaction terms, produced an overall classification accuracy of only $76.9 \%$, suggesting that the GAM was superior to the GLM. However, after subjecting these 2 models to cross validation to estimate their expected classification accuracy with new data, a different picture emerged with respect to their relative performance. Although the prediction accuracy of the GAM declined substantially (from $82.4 \%$ to $75.0 \%$; Table 4 ) in the cross validation, the prediction accuracy of the GLM remained relatively stable (76.9 to $75.0 \%)$. This difference indicates that the GAM, because of its greater number of estimated parameters, over-fitted the original data. Because the cross-validated prediction accuracy did not differ between models, the more stable and simpler GLM was chosen as the best model. A map showing the classification results of this model is provided in Figure 2.

One potential shortcoming with our method for predicting bottom trawlability is that it cannot be applied to the deeper parts of the survey area because of the requirement for a second echo in the acoustic data. The second echo is needed by the Echoview software to estimate 2 of the 9 parameters (hardness and second bottom length) and therefore contributes to prediction accuracy. However, resolution of the second echo in the acoustic data depends on water depth and ping rate, and the ping rate is limited to at least $1 \mathrm{~Hz}$ for vessel captains to recognize bottom features that are likely to result in net damage. This limitation on ping frequency, in turn, limits the maximum depth to $\sim 375 \mathrm{~m}$ at which our method could be applied. However, much of the deep areas of the continental slope tend to be relatively steep, which adversely affects the classifica- tion accuracy of single-beam systems (von Szalay and McConnaughey, 2002), and would therefore have been excluded anyway. Despite these limitations, only a relatively small portion of the survey area $(\sim 10 \%)$ needs to be excluded (Fig. 1).

Unlike earlier acoustic software for determining bottom types, such as the programs that were part of the QTC VIEW (Ellingsen et al., 2002) and RoxAnn (Greenstreet et al., 1997) seabed classification systems, the Echoview bottom typing module requires calibration of the echosounder so that the strength of the bottom echo can be interpreted directly. Because GOA survey vessels routinely perform an echosounder calibration with copper spheres at the beginning and ending of each survey, this additional requirement did not add an additional burden for the collection of acoustic data and presumably provided additional information that improved our ability to determine bottom trawlability.

Although the primary motivation for this study was to develop a method that can be used to estimate the relative proportions of trawlable and untrawlable areas in the GOA bottom trawl survey area so that abundance estimates derived from survey trawl catches are extrapolated only to trawlable areas, another application of this method is to improve survey efficiency. The current survey design process involves randomly selecting stations within the survey grid that have been either declared trawlable, on the basis of criteria specified in the introduction, or whose trawlability status is unknown. Stations that have been declared untrawlable are not part of the sampling pool. The selection of stations that are unclassified with respect to trawlability contributes to an inefficient survey method because these stations are sampled with equal probability and yet may result in much fruitless search 


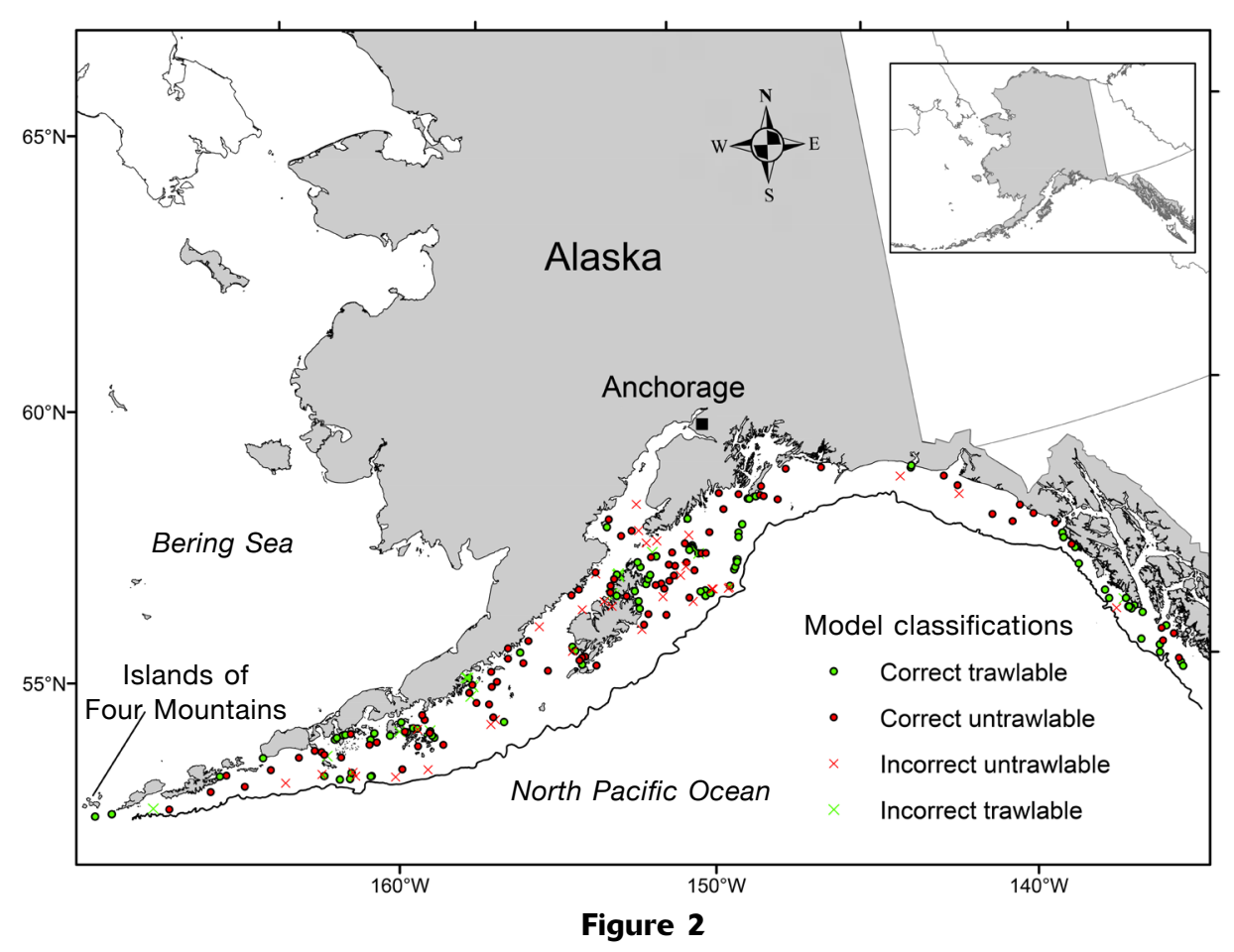

Bottom classification results of the best generalized linear model for 238 acoustic data segments that were collected in the Gulf of Alaska and used in the building and validation of this model. The segments, each represented by a symbol on the map at its collection area, are divided into 4 categories: area correctly classified as trawlable (green circles), area correctly classified as untrawlable (red circles), untrawlable area incorrectly predicted as trawlable (green x's), and trawlable area incorrectly predicted as untrawlable (red X's).

effort for trawlable ground in sampling cells that ultimately turn out to be untrawlable. Much of this inefficiency can be eliminated by minimizing the number of untrawlable sampling cells that make up the unclassified category of the sample of survey stations. This can be achieved by applying our model to the unclassified sampling cells so that a tentative trawlability status can be assigned to them. However, because of the lower confidence in the trawlability status of these sampling cells, it would not be appropriate to assign them binary sampling probabilities (0 or 1$)$ as is done with sampling cells whose trawlability status is determined by traditional means. On the other hand, it is not necessary to assign equal sampling probabilities to these model-classified cells as is currently the case with the unclassified sampling cells. Instead, higher sampling probabilities would be assigned to sampling cells that our model predicts to be trawlable than to those that our model predicts to be untrawlable. The ratio of these sampling probabilities is a function of the prediction accuracy of the model.

\section{Acknowledgments}

S. Kotwicki, S. Stienessen, W. Palsson, J. Napp, J. Thorson, and 2 anonymous reviewers provided valu- able comments which resulted in substantial improvements to the initial manuscript. J. Benson provided technical assistance with ArcMap in generating the figures. Funding was provided by the Office of Science and Technology, National Marine Fisheries Service, via the Improvement of Stock Assessment initiative. We thank all individuals involved in collecting the acoustic data on the FV Sea Storm during the 2013 GOA bottom trawl survey.

\section{Literature cited}

Anderson, J. T., R. S. Gregory, and W. T. Collins. 2002. Acoustic classification of marine habitats in coastal Newfoundland. ICES J. Mar. Sci. 59:156-167. Article Arlot, S., and A. Celisse.

2010. A survey of cross-validation procedures for model selection. Stat. Surv. 4:40-79. Article

Bartholomä, A.

2006. Acoustic bottom detection and seabed classification in the German Bight, southern North Sea. Geo-Mar. Lett. 26:177-184. Article

Busby, M. S., K. L. Mier, and R. D. Brodeur.

2005. Habitat associations of demersal fishes and crabs in the Pribilof Islands region of the Bering Sea. Fish. Res. 75:15-28. Article 
Clausen, D. M., and J. Heifetz.

2002. The northern rockfish, Sebastes polyspinis, in Alaska: commercial fishery, distribution, and biology. Mar. Fish. Rev. 64(4):1-28.

Cordue, P. L.

2007. A note on non-random error structure in trawl survey abundance indices. ICES J. Mar. Sci. 64:1333-1337. Article

Ellingsen, K. E., J. S. Gray, and E. Bjørnbom.

2002. Acoustic classification of seabed habitats using the QTC View system. ICES J. Mar. Sci. 59:825-835. Article

Foote, K. G., H. P. Knudsen, and G. Vestnes.

1983. Standard calibration of echo sounders and integrators with optimal copper spheres. Fisk.dir. Skr., Ser. Havunders. 17:335-346.

Freitas, R., S. Silva, V. Quintino, A. M. Rodrigues, K. Rhynas, and W. T. Collins.

2003. Acoustic seabed classification of marine habitats: studies in the western coastal-shelf area of Portugal. ICES J. Mar. Sci. 60:599-608. Article

Greenstreet, S. P. R, I. D. Tuck, G. N. Grewar, E. Armstrong, D. G. Reid, and P. J. Wright.

1997. An assessment of the acoustic survey technique, RoxAnn, as a means of mapping seabed habitat. ICES J. Mar. Sci. 54:939-959. Article

Jagielo, T., A. Hoffman, J. Tagart, and M. Zimmermann.

2003. Demersal groundfish densities in trawlable and untrawlable habitats off Washington: implications for the estimation of habitat bias in trawl surveys. Fish. Bull. 101:545-565.

Jones, D. T., C. D. Wilson, A. De Robertis, C. N. Rooper, T. C. Weber, and J. L. Butler.

2012. Evaluation of rockfish abundance in untrawlable habitat: combining acoustic and complementary sampling tools. Fish. Bull. 110:332-343.

Kloser, R. J., N. J. Bax, T. Ryan, A. Williams, and B. A. Barker.

2001. Remote sensing of seabed types in the Australian South East fishery; development and application of normal incidence acoustic techniques and associate 'ground truthing.' Mar. Freshw. Res. 52:475-489. Article

Maunder, M. N., and S. J. Harley.

2011. Using cross validation model selection to determine the shape of nonparametric selectivity curves in fisheries stock assessment models. Fish. Res. 110:283-288. Article

McConnaughey, R. A., and K. R. Smith.

2000. Associations between flatfish abundance and surficial sediments in the eastern Bering Sea. Can. J. Fish. Aquat. Sci. 57:2410-2419. Article

Pirtle, J. L., T. C. Weber, C. D. Wilson, and C. N. Rooper.

2015. Assessment of trawlable and untrawlable seafloor using multibeam-derived metrics. Methods Oceanogr. 12:18-35. Article

$\mathrm{R}$ Core Team.

2015. R: a language and environment for statistical com- puting. R Foundation for Statistical Computing, Vienna, Austria. [Available from website, accessed June 2015.]

Richards, L. J.

1986. Depth and habitat distributions of three species of rockfish (Sebastes) in British Columbia: observations from the submersible PISCES IV. Environ. Biol. Fish. 17:13-21. Article

Riegl, B. M., R. P. Moyer, L. J. Morris, R. W. Virnstein, and S. J. Purkis.

2005. Distribution and seasonal biomass drift macroalgae in the Indian River Lagoon (Florida, USA) estimated with acoustic seafloor classification (QTCView, Echoplus). J. Exp. Mar. Biol. Ecol. 326:89-104. Article

Rooper, C. N., G. R. Hoff, and A. De Robertis.

2010. Assessing habitat utilization and rockfish (Sebastes spp.) biomass on an isolated rocky ridge using acoustics and stereo image analysis. Can. J. Fish. Aquat. Sci. 67:1658 1670. Article

Stauffer, G. (compiler).

2004. NOAA protocols for groundfish bottom trawl surveys of the nation's fishery resources. NOAA Tech. Memo. NMFS-F/SPO-65, 205 p.

Stein, D. L., B. N. Tissot, M. A. Hixon, and W. Barss.

1992. Fish-habitat associations on a deep reef at the edge of the Oregon continental shelf. Fish. Bull. 90:540-551.

Thorson, J. T., M. E. Clarke, I. J. Stewart, and A. E. Punt.

2013. The implications of spatially varying catchability on bottom trawl surveys of fish abundance: a proposed solution involving underwater vehicles. Can. J. Fish. Aquat. Sci. 70:294-306. Article

von Szalay, P. G., and R. A. McConnaughey.

2002. The effect of slope and vessel speed on the performance of a single beam acoustic seabed classification system. Fish. Res. 54:181-194. Article

von Szalay, P. G., and N. W. Raring.

2016. Data report: 2015 Gulf of Alaska bottom trawl survey. NOAA Tech. Memo. NMFS-AFSC-325, 249 p.

Weber, T. C., C. Rooper, J. Butler, D. Jones, and C. Wilson.

2013. Seabed classification for trawlability determined with a multibeam echo sounder on Snakehead Bank in the Gulf of Alaska. Fish. Bull. 111:68-77. Article

Williams, K., C. N. Rooper, and R. Towler.

2010. Use of stereo camera systems for assessment of rockfish abundance in untrawlable areas and for recording pollock behavior during midwater trawls. Fish. Bull. 108:352-362.

Yoklavich, M. M., H. G. Greene, G. M. Cailliet, D. E. Sullivan, R. N. Lea, and M. S. Love.

2000. Habitat associations of deep-water rockfishes in a submarine canyon: an example of a natural refuge. Fish. Bull. 98:625-641.

Zimmermann, M.

2003. Calculation of untrawlable areas within the boundaries of a bottom trawl survey. Can. J. Fish. Aquat. Sci. 60: 657-669. Article 